\title{
RANCANGAN SISTEM INFORMASI ANEMIA PADA PLATFORM ONLINE "SRIKANDI HEALTH" BERBASIS PROGRESSIVE WEB APPS
}

\author{
Puji Handayani Putri ${ }^{1}$, Laeli Nur Hasanah ${ }^{2}$ \\ ${ }^{1}$ Program Studi Informatika Universitas PGRI Yogyakarta \\ 2Program Studi Gizi Universitas PGRI Yogyakarta
}

\begin{abstract}
Anemia is one of the nutritional problems that has the potential to hinder the development of the quality of Indonesian human resources. The support of science and information technology in the form of a website application can be a solution to facilitate education, monitoring and management of anemia so as to accelerate the handling of anemia. This study aims to design an anemia information system in the form of an online platform with the name "Srikandi Health" based on Progressive Web Apps to support the prevention of anemia in Indonesia in Indonesia. This research was conducted in December 2020 in Bantul, Yogyakarta. This study uses the prototype method. The stages of the prototype method start from gathering requirements, building prototyping, and evaluating protoptyping. The result of this research is the prototype of the online application "Srikandi Health" based on Progressive Web Apps. Conclusion Srikandi Health prototype is designed to meet the needs analysis of the system, namely to facilitate monitoring and prevention of anemia in adolescents. The suggestion of this research is the implementation of the system so that the system becomes more complete and can be applied to the wider community.
\end{abstract}

Keywords: anemia; Sri Kandi health; web apps

\begin{abstract}
Abstrak
Anemia menjadi salah satu masalah gizi yang berpotensi menghambat pembangunan kualitas sumber daya manusia Indonesia. Dukungan ilmu dan teknologi informasi dalam bentuk aplikasi website dapat menjadi solusi untuk kemudahan edukasi, pemantauan dan tatalaksana anemia sehingga mempercepat penanganan anemia. Penelitian ini bertujuan untuk merancang sistem informasi anemia berbentuk platform online dengan nama "Srikandi Health" yang berbasis Progressive Web Apps untuk mendukung penanggulangan anemia Indonesia di Indonesia. Penelitian ini dilakukan pada bulan Desember 2020 di Bantul, Yogyakarta. Penelitian ini menggunakan metode prototype. Tahapan metode prototype dimulai dari pengumpulan kebutuhan, membangun prototyping, dan evaluasi protoptyping. Hasil penelitian ini adalah protothype aplikasi online "Srikandi Health" berbasis Progressive Web Apps. Kesimpulan prototype Srikandi Health dirancang untuk memenuhi Analisa kebutuhan system yaitu mempermudah pemantauan dan penanggulangan anemia pada remaja. Saran penelitian ini adalah implementasi sistem supaya sistem menjadi lebih lengkap dan dapat diaplikasikan pada masyarakat secara luas.
\end{abstract}

Kata kunci: anemia; srikandi health; web apps

\section{PENDAHULUAN}

Anemia menjadi salah satu masalah gizi yang dapat menghambat pembangunan kualitas sumberdaya manusia. Anemia adalah kondisi kadar hemoglobin $(\mathrm{Hb})$ dan atau jumlah sel darah merah lebih rendah dari standar normal dan tidak memenuhi kebutuhan fisiologis tubuh. ${ }^{1}$ Anemia telah berdampak pada hampir sepertiga populasi dunia ${ }^{2}$ dan masih banyak ditemukan di berbagai negara termasuk Indonesia. Jenis anemia yang paling umum 
dialami di dunia adalah anemia defisiensi besi. Riset Kesehatan Dasar RI tahun 2018 melaporkan jumlah ibu hamil yang mengalami anemia meningkat menjadi 48,9\% dari 37,1 \% tahun 2013 dengan proporsi terbesar ada di kelompok umur 15-24 tahun. ${ }^{3}$ Sebanyak 84,6\% anemia pada ibu hamil terjadi pada kelompok umur 15-24 tahun.

Anemia berdampak pada morbiditas dan mortalitas pada wanita dan anak-anak, ${ }^{4,5}$ komplikasi kehamilan dan kelahiran, ${ }^{6}$ resiko tinggi bayi lahir rendah (BBLR), ${ }^{7}$ dan resiko tinggi bayi lahir prematur, ${ }^{7}$ penurunan produktivitas kerja pada orang dewasa, ${ }^{8}$ gangguan perkembangan kognitif dan perilaku pada anak-anak. ${ }^{9}$ Selain itu, anemia juga berpotensi memiliki kerugian ekonomi sekitar Rp 62 triliun per tahun atau 0,711\% PDB Indonesia. ${ }^{10}$

Ada dua faktor yang menyebabkan anemia defisiensi besi yakni penyebab langsung dan penyebab tidak langsung. ${ }^{11}$ Penyebab anemia secara langsung yakni kurangnya kadar zat besi dalam darah akibat asupan makanan sumber zat besi kurang ${ }^{12}$ dan kondisi tubuh yang terinfeksi penyakit seperti kecacingan dan malaria. Penyebab tidak langsung seperti pola asuh keluarga, kurangnya akses fasilitas kesehatan dan akses pangan keluarga. Anemia dapat terjadi pada semua jenis kelamin. Prevalensi anemia di Indonesia tahun 2013 pada perempuan $(27,2 \%)$ lebih tinggi dibandingkan pada laki-laki $(20,3 \%){ }^{3}$ Perempuan rentan terkena anemia karena mengalami masa menstruasi yang mengakibatkan kehilangan zat besi dua kali lebih tinggi dibandingkan laki-laki. ${ }^{13}$

Upaya pencegahan dan penanggulangan masalah kesehatan khususnya anemia perlu didukung oleh teknologi informasi agar penyelesaian semakin signifikan dan efektif. Beberapa hasil penelitian yang melaporkan manfaat teknologi informasi untuk penanggulangan masalah gizi antara lain aplikasi android Anemoinfo dapat menjadi alternatif sarana yang cukup efektif untuk meningkatkan pengetahuan anemia pada remaja ${ }^{14}$ dan aplikasi mobile health untuk evaluasi dan monitoring stunting. ${ }^{15}$ Perkembangan teknologi saat ini telah berdampak pada penggunaan smartphone yang semakin meningkat yang mendorong kemudahan akses informasi secara online termasuk informasi kesehatan anemia. Asosiasi Penyelenggara Jasa Internet Indonesia (APJII) tahun 2018 melaporkan setiap hari terjadi pertumbuhan jumlah pengguna internet dari 143,26 juta orang menjadi 171,17 juta orang. Pemanfaatan teknologi dan informasi dapat menjadi solusi untuk kemudahan edukasi, pemantauan dan tatalaksana masalah gizi termasuk anemia sehingga mempercepat penanganan anemia.

Salah satu platform online yang berpotensi untuk mendukung penanggulangan anemia adalah Website Application (Web Apps). Progresif Web Apps memiliki beberapa keunggulan antara lain kemudahan pengguna karena tidak memerlukan instalasi, aplikasi dimuat dengan cepat meskipun berada dalam jaringan yang buruk. Ketika pengguna meninggalkan browser, dan kembali lagi membuka aplikasi tersebut pada jaringan buruk atau tanpa jaringan sekalipun pengguna tidak akan kehilangan User Interface dan data-data terakhir. 
Platform Progressive Web Apps memiliki manfaat bagi semua orang yang terlibat baik itu remaja maupun tenaga kesehatan. Progressive Web Apps memungkinkan untuk tenaga kesehatan memberikan pelayanan konsultasi dan pemantauan pada remaja dalam menanggulangi anemia. Selain itu pada Progressive Web Apps dapat ditambahkannya media edukasi tentang anemia remaja sebagai alat bantu dalam penyuluhan menanggulangi anemia remaja. Saat ini pengembangan sistem informasi kesehatan untuk penanggulangan anemia berbasis Progressive Web Apps di Indonesia belum pernah dilakukan oleh karena itu penelitian ini bertujuan untuk merancang sistem informasi kesehatan penanggulangan anemia berbentuk platform online berbasis Progressive Web Apps.

\section{METODE PENELITIAN}

Penelitian ini dilakukan pada bulan Desember 2020 di SMA PGRI 1 Kasihan, Bantul, DIY. Metode penelitian yang digunakan dalam penelitian ini adalah metode prototype. Ogedebe, dkk (2012). Metode prototype merupakan metode pengembangan perangkat lunak, yang berupa model fisik kerja system dan berfungsi sebagai versi awal dari system. Metode prototyping akan menghasilkan prototype system sebagai perantara pengembang dan pengguna agar dapat berinteraksi dalam proses kegiatan pengembangan sistem informasi. Tahapan metode prototype dimulai dari pengumpulan kebutuhan, membangun prototyping, evaluasi protoptyping. Pengumpulan kebutuhan sistem dilakukan melalui observasi langsung pada sasaran di lokasi penelitian yaitu pada siswa remaja. Siswa remaja diberikan beberapa pertanyaan tentang anemia sehingga data tersebut digunakan untuk menentukan analisis kebutuhan sistem informasi kesehatan. Analisis kebutuhan sistem yang diperoleh selanjutnya digunakan untuk membangun prototyping. Langkah selanjutnya yakni evaluasi protoptyping dengan cara mengevaluasi perancangan sistem informasi kesehatan yang telah disesuaikan dengan analisis kebutuhan sistem pada remaja. Perancangan sistem bersifat user friendly untuk remaja dan tenaga kesehatan. Evaluasi menggunakan quisioner online yang meliputi pertanyaan seputar kualitas sistem yang digunakan.

\section{HASIL PENELITIAN}

Berdasarkan quisioner online yang diberikan pada remaja SMA PGRI 1 Kasihan dan tenaga Kesehatan di Puskesmas Bantul I, menunjukkan bahwa sebagian besar subjek setuju dan sangat setuju (78,6\%) bahwa sistem informasi kesehatan pada "Srikandi Health" memenuhi kebutuhan pemrosesan informasi di area tanggung jawab di area tanggung jawab pengguna, sistem informasi kesehatan "Srikandi Health" efisien $(71,4 \%)$ dan efektif $(71,4 \%)$ serta secara sebagian besar subjek $(71,4 \%)$ setuju bahwa sistem informasi "Srikandi Health" memberikan kepuasan bagi pengguna. Siswa dan guru memberikan salah satu kesimpulan bahwa sistem penanggulangan anemia sangat diperlukan untuk cek kesehatan remaja. Penanggulangan anemia perlu disajikan dalam bentuk sistem informasi 
kesehatan berbasis Progressive Web Apps untuk memudahkan dalam penggunaan karena ditampilkan secara menarik dan dapat diakses dimanapun kapanpun dengan mudah. Selain itu ada kebutuhan fitur edukasi anemia yang dapat menyajikan informasi terkini atau up to date mengenai anemia remaja seperti dampak anemia, bahaya anemia, dan penanggulangan anemia remaja. Dari analisa kebutuhan sistem tersebut maka tahapan selanjutnya adalah membangun prototyping. Perancangan dibuat userfriendly yaitu perancangan sistem yang ramah dan memudahkan penggunanya dalam mengoperasikan sistem.

\section{PEMBAHASAN}

Penelitian yang dilakukan oleh Atika Hendryani (2020) tentang pengembangan aplikasi mobile health berbasis android untuk monitoring dan evaluasi stunting. Tujuan penelitian ini ialah membangun aplikasi kesehatan bergerak berbasis android untuk memantau dan mencegah stunting. Namun aplikasi ini butuh proses penginstalan pada perangkat android hal ini memungkinkan user terutama ibu-ibu mengalami kesulitan. Oleh karena itu peneliti akan membuat pengembangan teknologi kesehatan lebih mudah dengan cara cukup mengakses url web apps, aplikasi siap digunakan.

Penelitian yang dilakukan oleh Fifi Dwijayanti, dkk. (2020) tentang pentingnya kesehatan masyarakat, edukasi dan pemberdayaan perempuan untuk mengurangi stunting di negara berkembang menyatakan bahwa banyak faktor risiko yang mempengaruhi stunting. Stunting disebabkan oleh faktor multidimensi dan tidak hanya disebabkan oleh faktor malnutrisi yang dialami ibu hamil dan anak balita, akan tetapi tenaga kesehatan masyarakat dalam memberikan informasi dan edukasi serta upaya pemberdayaan wanita, khususnya ibu sangat penting dalam menurunkan stunting. Oleh karena itu penulis akan menambahkan fitur edukasi pada web apps yang akan dibangun, tepatnya edukasi anemia pada remaja.

Berdasarkan Rujukan penelitian tersebut, ditemukan analisa kebutuhan sistem yaitu sistem dibuat berplatform Progressive Web Apps untuk memudahkan penggunanya tanpa harus download dan install dalam kapasitas besar. Disamping itu perlu adanya fitur penyuluhan dalam bentuk edukasi penanggulangan anemia, sistem dapat komunikasi 2 arah melalui fitur whatsapp yang ada guna pemantauan tenaga kesehatan pada pasien remaja. Berikut merupakan implementasi dari analisa kebutuhan sistem. 


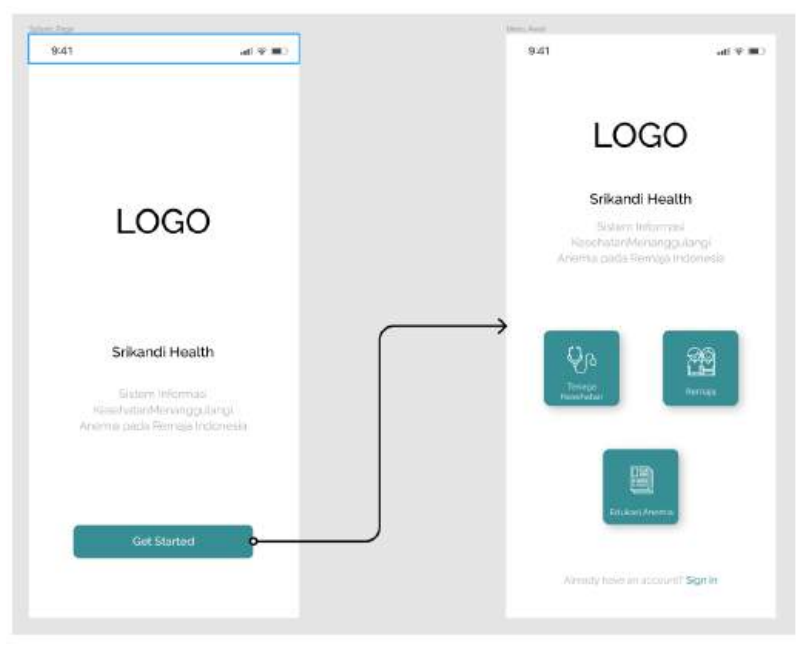

\section{Gambar 1. Tampilan halaman general}

Halaman general terdiri atas halaman menu utama dan halaman splash. Halaman splash ini muncul pertama kali. User cukup klik tombol Get Started untuk menuju halaman menu utama. Menu utama terdiri atas 3 menu tombol yaitu tenaga kesehatan, remaja, dan edukasi anemia. Masing-masing dari user dapat menyesuaikan login sebagai tenaga kesehatan atau sebagai remaja. User dapat melakukan pendaftaran terlebih dahulu dan user dapat login apabila sudah memiliki akun. Bagian fitur edukasi anemia menyajikan informasi up to date seputar anemia remaja. Admin berperan untuk mensubmit artikel anemia remaja. Setiap user dapat mengkaji fitur edukasi anemia dengan mudah.

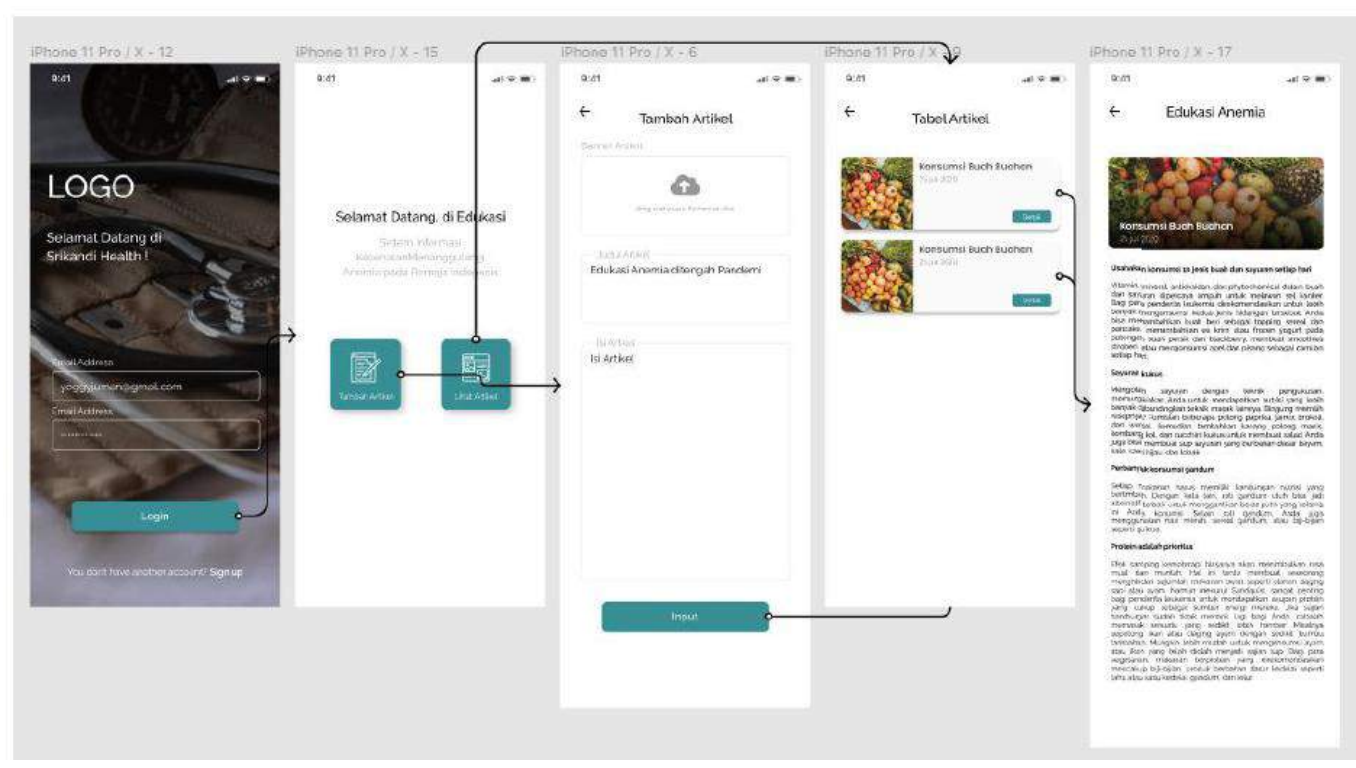

Gambar 2. Tampilan halaman edukasi anemia

User dapat mengkaji informasi seputar anemia melalui tombol edukasi anemia pada menu utama. User login terlebih dahulu dengan memasukkan username dan password. Ada 2 menu edukasi yaitu tombol tambah artikel dan lihat artikel. User dapat melihat dan mengkaji setiap artikel yang telah disubmit oleh admin. 


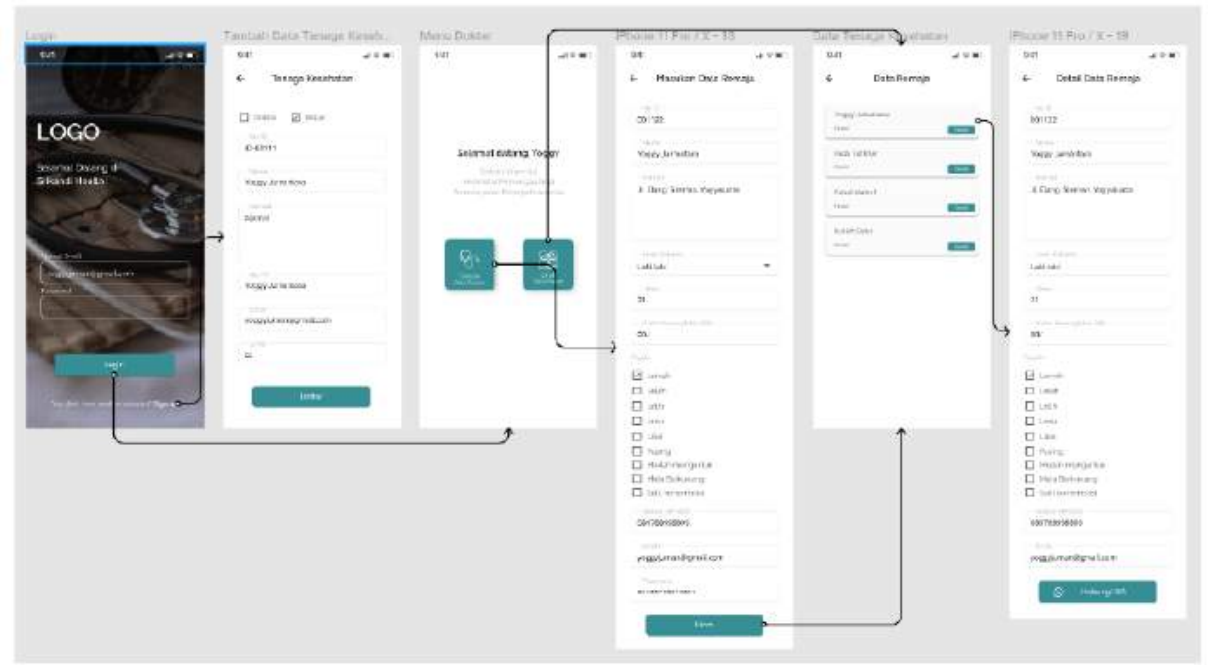

\section{Gambar 3. Tampilan halaman tenaga kesehatan}

Halaman tenaga kesehatan merupakan halaman khusus login user tenaga kesehatan yaitu Dokter dan Bidan. Tenaga kesehatan dapat melakukan pendaftaran untuk mendapatkan akun login. Tenaga kesehatan dapat sign in menggunakan akun login yang telah dibuat. Terdapat 2 menu utama yaitu tambah data pasien dan lihat data pasien. Menu tambah data pasien berfungsi untuk menambah data pasien dengan cara tenaga kesehatan menginputkan data pasien berupa no_id pasien, nama, alamat, jenis kelamin, umur, gejala, nomor WhatsApp remaja, akun remaja (email dan password). Menu lihat data pasien berfungsi untuk melihat data remaja lengkap dengan informasi gejala yang dialami remaja. Tenaga kesehatan dapat menghubungi remaja yang bersangkutan bila ditemukan adanya gejala anemia.

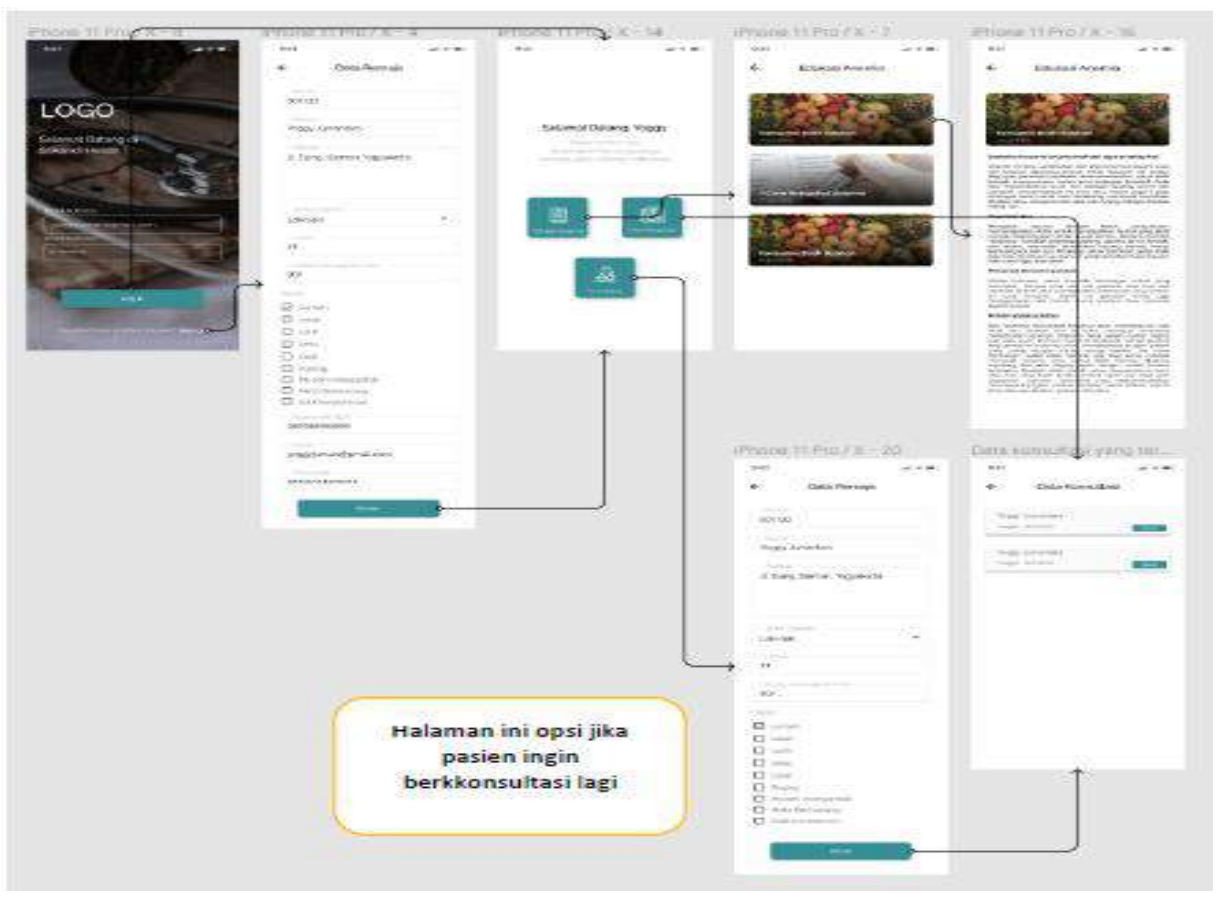

Gambar 4. Tampilan Halaman Pasien Remaja 
Halaman remaja terdiri atas 3 menu utama yaitu pendaftaran remaja, konsultasi remaja, data konsultasi. Remaja dapat melakukan pendaftaran remaja dengan cara menginputkan no_id pasien, nama, alamat, jenis kelamin, umur, gejala, nomor WhatsApp remaja, akun remaja (email dan password). Remaja dapat konsultasi kepada tenaga kesehatan seputar anemia remaja. Remaja dapat melihat detail konsultasi dan melakukan konsultasi ulang.

\section{SIMPULAN DAN SARAN}

Rancangan sistem informasi kesehatan penanggulangan anemia remaja ini berupa prototype yang dikembangkan berdasarkan data analisa kebutuhan sistem yang dibutuhkan untuk menanggulangi anemia remaja. Rancangan antarmuka sistem Srikandi Health ini dibuat berbasis Progressive Web Apps untuk memudahkan pengguna tanpa harus download install dalam kapasitas besar. Rancangan antarmuka sistem dibuat dengan menambahkan fitur edukasi anemia untuk memudahkan tenaga Kesehatan dalam pemantauan anemia dan memberikan penyuluhan seputar penanggulangan anemia pada remaja. Rancangan antarmuka sistem bersifat User Friendly sehingga memudahkan pengguna dalam mengoperasikannya. Kesimpulan prototype Srikandi Health dirancang untuk memenuhi Analisa kebutuhan system yaitu mempermudah pemantauan dan penanggulangan anemia pada remaja. Saran penelitian sistem berikutnya yaitu pengembangan sistem atau implementasi sistem supaya sistem menjadi lebih lengkap dan dapat diaplikasikan pada masyarakat secara luas.

\section{DAFTAR PUSTAKA}

1. Germain, A. R. D. levine susan hanson maureen. Anemia epidemiology, pathophysiology, and etiology in low-and middle-income countries. Physiol. Behav. 176, 139-148 (2017).

2. Kassebaum, N. J. et al. A systematic analysis of global anemia burden from 1990 to 2010. Blood 123, 615-624 (2014).

3. Badan Penelitian dan Pengembangan Kehan. Laporan_Nasional_RKD2018_FINAL.pdf. Badan Penelitian dan Pengembangan Kesehatan 198 (2018).

4. Black, R. E. et al. Maternal and child undernutrition and overweight in low-income and middle-income countries. Lancet 382, 427-451 (2013).

5. Scott, S. P., Chen-Edinboro, L. P., Caulfield, L. E. \& Murray-Kolb, L. E. The impact of anemia on child mortality: An updated review. Nutrients 6, 5915-5932 (2014).

6. Haider, B. A. et al. Anaemia, prenatal iron use, and risk of adverse pregnancy outcomes: Systematic review and meta-analysis. BMJ 347, 1-19 (2013).

7. Beckert, R. H., Baer, R. J., Anderson, J. G., Jelliffe-Pawlowski, L. L. \& Rogers, E. E. Maternal anemia and pregnancy outcomes: a population-based study. J. Perinatol. 39, 
911-919 (2019).

8. Khatun, T. et al. Anemia among Garment Factory Workers in Bangladesh. Middle East J. Sci. Res. 16, 502-507 (2013).

9. Jáuregui-Lobera, I. Iron deficiency and cognitive functions. Neuropsychiatr. Dis. Treat. 10, 2087-2095 (2014).

10. Mangalik, G., Martianto, D. \& Sukandar, D. Estimasi Potensi Kerugian Ekonomi Dan Biaya Penanggulangan Akibat Anemia Di Indonesia. Estimasi Potensi Kerugian Ekon. Dan Biaya Penanggulangan Akibat Anemia Di Indones. 11, 237-246 (2016).

11. Priyanto, L. D. The Relationship of Age, Educational Background, and Physical Activity on Female Students with Anemia. J. Berk. Epidemiol. 6, 139 (2018).

12. Safyanti, A. \& Andrafikar, A. Perilaku Makan Dan Kejadian Anemia Pada Mahasiswi. J. Sehat Mandiri 13, 1-9 (2018).

13. Simanungkalit, S. F. \& Simarmata, O. S. Pengetahuan dan Perilaku Konsumsi Remaja Putri yang Berhubungan dengan Status Anemia. Bul. Penelit. Kesehat. 47, 175182 (2019).

14. Saraswati, R. S., Kartini, A. \& Agushybana, F. Pengaruh Aplikasi Android Aneminfo terhadap Pengetahuan dan Sikap Remaja Putri terkait Anemia Defisiensi Besi. J. Promosi Kesehat. Indones. 15, 65-69 (2020).

15. Hendryani, A. \& Susana, E. Pengembangan Aplikasi Mobile Health Berbasis Android untuk Monitoring dan Evaluasi Stunting. J. Sehat Mandiri 15, 24-32 (2020). 